\title{
Body integrity identity disorder and Gender Dysphoria: A pilot study to investigate similarities and differences
}

\author{
Antonia Ostgathe, Thomas Schnell, Erich Kasten \\ MSH Medical School Hamburg, University of Applied Sciences and Medical University, Am Kaiserkai 1, D-20457 Hamburg, Germany
}

\section{Email address:}

antonia@ostgathe.info (A. Ostgathe), Thomas.Schnell@medicalschool-hamburg.de (T. Schnell), Erich.Kasten@medicalschool-hamburg.de (E. Kasten)

\section{To cite this article:}

Antonia Ostgathe, Thomas Schnell, Erich Kasten. Body Integrity Identity Disorder and Gender Dysphoria: A Pilot Study to Investigate Similarities and Differences. American Journal of Applied Psychology. Vol. 3, No. 6, 2014, pp. 138-143. doi: 10.11648/j.ajap.20140306.14

\begin{abstract}
Objective: Body Integrity Identity Disorder (BIID) describes a phenomenon in which physically healthy people feel the constant desire for an impairment of their body. M. First [4] suggested to classify BIID as an identity disorder. The other main disorder in this respect is Gender Dysphoria. In this paper these phenomena are compared. Method: A questionnaire survey with transsexuals (number of subjects, $\mathrm{N}=19)$ and BIID sufferers $(\mathrm{N}=24)$ measuring similarities and differences. Age and educational level of the subjects are predominantly matched. Results: No differences were found between BIID and Gender Dysphoria with respect to body image and body perception (U-test: $p$-value $=.757)$, age of onset $(p=.841)$, the imitation of the desired identity $(\mathrm{p}=.699$ and $\mathrm{p}=.938)$, the etiology $(\mathrm{p}=.299)$ and intensity of desire $(\mathrm{p}=.989$ and $\mathrm{p}=.224)$ as well as in relation to a high level of suffering and impaired quality of life $(\mathrm{p}=.066)$. Conclusion: There are many similarities between BIID and Gender Dysphoria, but the sample was too small to make general statements. The results, however, indicate that BIID can actually be classified as an identity disorder.
\end{abstract}

Keywords: Body Integrity Identity Disorder, BIID, Xenomelia, Amputation, Gender Dysphoria, Transsexualism, Identity, Gender Identity Disorder, Identity Disorder

\section{Introduction}

Body Integrity Identity Disorder (BIID), as term introduced by First [4,5] describes a very rare phenomenon which causes the affected people to feel the persistent desire for a physical impairment, usually in the form

of an amputation of a limb or a paraplegia. Affected persons often suffer intensely from their growing desire and they often imitate the desired physical condition. It is largely unknown how many people are affected by BIID. The desire for the self mutilation offends the current aesthetic and ethical ideas, at least in the Western cultural sphere. This is also reflected from a legal point of view. Physicians are required to maintain or re-establish physical health and integrity, but not to amputate a healthy limb. Regarding BIID, this starts a medical-ethical debacle $[3,11]$. Severe self-injury are often an initial attempt to provoke the desired amputations. In addition, eventual expensive operations abroad show the intense psychological strain on the affected people. And last, but not least, they often accept life-threatening circumstances $[4,16]$.
Due to its persisting insufficient research status, the phenomenon of BIID has not yet been added to the diagnostic systems ICD (International Classification of Diseases) or DSM (Diagnostic and Statistical Manual of Mental Disorders). Therefore, the afflicted people cannot hope for medical attendance.

Through further research concerning the phenomenon of BIID it is essential to accomplish the inclusion to the diagnostic systems and to improve the situation of people suffering from BIID and to allow official treatment and therapy at least. The following survey should contribute to the differential diagnosis between BIID and Gender Dysphoria in this context.

\section{Hypotheses}

Basis of this study are the ideas of Nieder and Richter-Appelt [14] established on theoretical considerations a few years ago, which were empirically and quantitatively investigated in a slightly different way in this study. Furthermore, self established hypotheses were tested. 
Until now there are no empirically found results of this comparison in the literature. Therefore it was not possible to indicate a specific direction of the alternative hypotheses, i.e. whether the value of the investigated variables is stronger or weaker in BIID than in Gender Dysphoria. Thus, two-tailed questions had to be examined.

Hypotheses on the following topics were investigated: body image and body perception, pretending \& cross-dressing, development of the desire, genesis of the wish, acquisition of equipment for the approximation, the intensity of the desire, influence of sexual components and social life.

\section{Methods}

In order to collect the data, a self-created online questionnaire was used, based on the "Düsseldorf questionnaire for transgender identity" (Düsseldorfer Fragebogen zur Transidentität [17]). The questionnaire was divided into two parts. In the first part ( 7 items) socio-demographic data of the subjects were recorded, e.g. the (biological) sex, age, number of years of education, marital status and already achieved or still desired (surgical) changes. The second part consisted of 41 items, which were related to additional specific hypotheses.

The subjects were informed about the goals of the study and that the collected data would be published anonymously. To check the reliability four questions with similar content were placed at different positions in the questionnaire.

The answers could be allocated on a scale from 0 (as not appropriate at all) to 100 (as perfectly appropriate) in intervals of ten (0-10-20, etc.). For statistical analysis, these values were transformed to a 1 to 11 scale.

The following methods were used: In addition to the calculation of frequencies, means and standard deviations, the Chi-Square test and the Mann-Whitney U-test as nonparametric tests of significant differences between the independent samples were performed.
The contact to affected people was established with the help of Internet forums and support groups.

Exclusion criteria: Subjects with intersex syndrome were excluded, as well as questionnaires with missing correlation of the items of reliability. Cases of more than $20 \%$ missing answers were excluded, too.

38 BIID sufferers and 30 transsexual subjects answered the questionnaires. The drop-out rate (after application of the exclusion criteria, see above) amounted to 14 people suffering from BIID and 11 transsexuals. In the end, the data of 24 BIID sufferers and 19 transsexual participants were included in the analysis. In addition to the body changes referred to in Table 1 , the following requests were expressed in the sample of BIID sufferers: "amputation of both feet", "deformed feet", "achieved - atrophy of thigh - slightly stiff knee", "incontinence", "right index finger", "strong dystrophy of the legs" and "right toe amputation". Other changes mentioned in the sample of transsexual subjects included: "face feminization", "body hair epilation", "vocal cords surgery", "vocal enhancement".

Further information about the socio-demographic data of the two samples is represented in Table 1.

\section{Results}

With respect to the etiology of the desire, the hypothesis was confirmed, that both, BIID sufferers as well as transsexuals, cannot give a rational explanation for their desire.

No substantial explanations of cause and effect could be given, but it was found that both, BIID sufferers and people diagnosed with Gender Dysphoria, primarily attribute the etiology to biological-genetic reasons (see Table 2).

Concerning these reasons, no significant differences between the two samples could be revealed (Chi-Square value: 2.418, df: 2, two-sided two-tailed asymptotic significance: $p=.299$ ).

\subsection{Sample}

Table 1. Socio-demographic data and desired/already achieved measures.

\begin{tabular}{|c|c|c|c|c|c|}
\hline & BIID $(n=24)$ & Gender Dysphoria $(n=19)$ & df & value & $\mathbf{p}$ \\
\hline $\operatorname{Sex}(m / f)$ & $21 / 1$ & $7 / 12$ & 1 & $16.175^{1}$ & $\leq .001$ \\
\hline $\operatorname{Age}^{3}(\mathrm{M}(\mathrm{SD}))$ & $44.29(10.19)$ & $43.84(14.08)$ & & $224,5^{2}$ & .932 \\
\hline Years of education (m (SD)) & $16.71(3.25)$ & $16.08(4.74)$ & & $211,5^{2}$ & .683 \\
\hline $\begin{array}{l}\text { Marital status (Married/Partnership, Di- } \\
\text { vorced, Widowed, Single }\end{array}$ & $\begin{array}{l}15,0,2,6 \\
\text { (One missing data) }\end{array}$ & $5,3,0,11$ & 3 & $11.191^{1}$ & .011 \\
\hline $\begin{array}{l}A=\text { subjects who already achieved surgical } \\
\text { changes ( } n) \\
B=\text { subjects who did not achieve surgical or } \\
\text { other changes yet (n) }\end{array}$ & $\begin{array}{l}A=5 \\
B=18 \\
\text { (One missing data) }\end{array}$ & $\begin{array}{l}A=11 \\
B=8\end{array}$ & 1 & $5.768^{1}$ & .016 \\
\hline $\begin{array}{l}\text { Intended or already achieved body changes } \\
\text { (n) }\end{array}$ & $\begin{array}{l}\text { Above-knee amputation left }=7 \\
\text { Above-knee amputation right }=8 \\
\text { Upper arm-or forearm amputation }=1 \\
\text { Paraplegia }=9\end{array}$ & $\begin{array}{l}\text { Change of legal gender }=18 \\
\text { Hormonotherapy }=18 \\
\text { Change of name }=18 \\
\text { Genital surgery }=12 \\
\text { Surgical intervention (breast) }=11 \\
\text { Epilation (beard) }=11\end{array}$ & & & \\
\hline
\end{tabular}

Annotations: $\mathrm{N}=$ number of subjects, $\mathrm{M}=$ mean value, $\mathrm{SD}=$ standard deviation; $\mathrm{p}=$ significance; $1=$ chi2 $; ; 2=\mathrm{U}-\mathrm{Test} ; \mathrm{m} / \mathrm{f}=$ male $/ \mathrm{female} ; 3=\mathrm{years}$ 
The justification of BIID sufferers was multifaceted. The reasons included triggering childhood events, restoring a congruence between sentiment and body, feeling attracted by people with physical disabilities, a fascination for physically impaired people, as well as the perception of body impairment as a proper way of living. Five subjects expressed that the desire had simply (always) been there and could not be removed: "It is like it is." One subject asked why an explanation is necessary.

Regarding the question of body image and body perception, the hypothesis could be proven that both, BIID sufferers and transsexuals, have the strong feeling that their biological body does not match their mental body image. The two samples showed similarities in answering the item (BIID: $M=9.08$, $\mathrm{SD}= \pm$ 3.23; Gender Dysphoria: $\mathrm{M}=9.05, \quad \mathrm{SD}= \pm 2.72$; $\mathrm{U}$-value $=216.5$; significance (U-test): $\mathrm{p}=.757$,). In contrast, it could be shown, that while transsexuals face their assigned sex with rejection, BIID sufferers face their task-limb only with indifference. Here, the data revealed significant differences between the two groups (see Table 3 ).

Concerning the development of the desire, the hypothesis was confirmed that both, BIID sufferers and transsexuals, show a beginning of their desire in childhood or early adolescence.

First doubts about the identity as an intact human being or about the gender identity were seen in the BIID sufferers at the average age of 10.76 years $(\mathrm{SD}= \pm 5.27)$ and 13.00 years $(\mathrm{SD}= \pm 11.73)$ in the transsexual subjects. The significance in the U-test was .953 (U-value=117.0).

The desire to live in the body of a physically impaired person or the opposite gender, manifested itself in the BIID sufferers in the average age of 10.09 years $(\mathrm{SD}= \pm 4.51)$ and at the average age of $12.50(\mathrm{SD}= \pm 11.91)$ in the transsexual subjects. The significance in the U-test amounted to .841 (U-value=154.0).

Another assumption on pretending and cross-dressing proposed that BIID sufferers, as well as transsexual persons, have been imitating their desired appearance for approximation and testing long before the surgery. There were no significant group differences. A significant difference was only shown for items 3 and 4, i.e. both groups start early to imitate the desired appearance, though the number of hours differs significantly (see Table 4).

For the hypothesis about the intensity of the desire it has been statistically proven that both, BIID sufferers and transsexual persons, have the feeling that they can live in line with their experienced identity only through surgical changes (BIID: $\mathrm{M}=9.42, \mathrm{SD}= \pm 3.08$; transsexuals: $\mathrm{M}=9.47, \mathrm{SD}= \pm$ 2.80; U-value $=227.5$; significance (U-test): $\mathrm{p}=.989$ ).

There are also no significant differences between the groups with regard to a simplified acceptation of the body with psychotherapy (BIID: $\mathrm{M}=2.83, \mathrm{SD}= \pm 2.53$; transsexuals: $\mathrm{M}=2.05, \mathrm{SD}= \pm 1.84$; $\mathrm{U}$-value $=182.5$; significance (U-test): $\mathrm{p}=.224)$.

Concerning the influence of sexual components a significant difference between BIID sufferers and transsexuals could be revealed: a sexual component amplifies the desire for surgical alteration (BIID: $\mathrm{M}=6.33, \mathrm{SD}= \pm 3.61$; transsexuals: $\mathrm{M}=3.83$ $\mathrm{SD}= \pm 3.60$; $\mathrm{U}$-value=132.0; significance (U-test): $\mathrm{p}=.029$ ).

Finally, no significant group differences could be assessed with regard to a severe psychological strain and restrictions in quality of life without achieving the surgical goal (BIID: $\mathrm{M}=8.42, \quad \mathrm{SD}= \pm 3.02 ; \quad$ transsexuals: $\mathrm{M}=9.63, \quad \mathrm{SD}= \pm 2.34$; $\mathrm{U}$-value=155.5; significance (U-test): $\mathrm{p}=.066)$.

Table 2. Reason for genesis of BIID and Gender Dysphoria

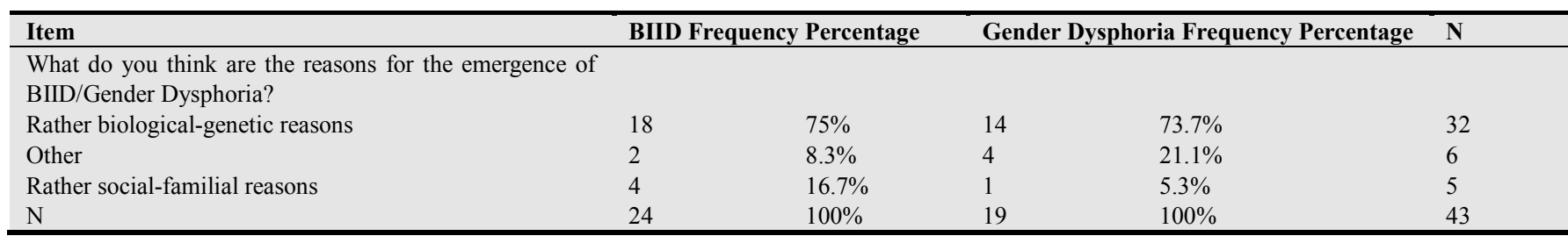

\section{Discussion}

The main conclusion is that several important similarities were revealed between BIID and Gender Dysphoria. The groups were comparable in terms of age and years of education. The statistical analysis confirmed that BIID-sufferers, as well as transsexuals, were unable to give a rational explanation for their desire for a considerable change of their body. It was found that the subjects in both groups stated primarily biological-genetic causes as the reason for their desire, ahead of the social-familial causes or other components (see Table 2). This might be traced back to the numerous biological and genetic studies in the field of transsexuality that support the intentions to depathologize Gender Dysphoria as a normal variation [6]. The responses of BIID sufferers did not provide any reasonable explanation for their request. There was a variety of assumptions expressed (see above).

Table 3. Rejection of altering bodily features

\begin{tabular}{|c|c|c|c|c|}
\hline Item & BIID $M$ and SD & Gender Dysphoria $M$ and SD & Value (U-Test) & Significance (U-Test) \\
\hline $\begin{array}{l}\text { I feel a strong rejection of the body } \\
\text { featuresthat I wish to change. } \\
\mathrm{N}=24 \text { (BIID) } \\
\mathrm{N}=19 \text { (Gender Dysphoria) }\end{array}$ & $4.50 \pm 3.16$ & $8.68 \pm 3.06$ & 74.5 & $\leq .001$ \\
\hline
\end{tabular}


Many of these statements can also be found in previous studies $[2,4,8,9]$.

The evaluation of the findings showed similarities of the feeling that the own biologically healthy or assigned body does not correspond to the subjective mental body image. Both groups confirmed this to a great extent. This incongruence between the own body and the feeling how the body should be was the most important reason to justify the desire for a surgical approximation. This desired surgery in both samples was associated with the hope to establish a congruence between (a) the subjective body image and (b) the visible, physical body. These results support the assumption of Hilti \& Brugger [7] that the feeling of an in-trinsic property of specific body parts lacks in BIID-sufferers.

In the following hypothesis the assumption was tested, that transsexuals would be negative towards their assigned gender characteristics whereas BIID sufferers be rather indifferent towards the limb that should be amputated (see Table 3).

In previous investigations it was already proven that BIID-affected persons have no negative associations in regard to their affected body parts [2,8], which supports the results of this study. In comparison, it was found that the body parts transsexuals desire to change were very strongly rejected up to the point of hatred $[1,19]$.

Table 4. Performing of Pretending and Cross-Dressing

\begin{tabular}{|c|c|c|c|c|c|c|}
\hline Item & $\begin{array}{l}\text { BIID } \\
\text { M and SD }\end{array}$ & & $\begin{array}{l}\text { Gender Dys } \\
M \text { and SD }\end{array}$ & horia & $\begin{array}{l}\text { Value } \\
\text { (U-Test) }\end{array}$ & $\begin{array}{l}\text { Significance } \\
\text { (U-Test) }\end{array}$ \\
\hline $\begin{array}{l}\text { If you've ever faked a physical disability: At what age } \\
\text { did you first use specific aids for the desired disability? }\end{array}$ & Cov. & Cov. & & & & \\
\hline Covert: (Cov.) & 14.82 & \pm 10.94 & & & & \\
\hline $\begin{array}{l}\mathrm{N}=22 \text { (BIID) } \\
\mathrm{N}=13 \text { (Gender Dysphoria) }\end{array}$ & Pub. & Pub. & & & Cov. & Cov. \\
\hline $\begin{array}{l}\text { Appear in public: (Pub.) } \\
\mathrm{N}=18 \text { (BIID) }\end{array}$ & 25.28 & \pm 13.10 & & & 131.5 & .699 (n.s.) \\
\hline $\begin{array}{l}\mathrm{N}=18 \text { (Gender Dysphoria) } \\
\text { 2. Cross-Dressing: }\end{array}$ & & & Cov. & Cov. & Pub. & Pub. \\
\hline $\begin{array}{l}\text { If you have ever worn clothes of the opposite sex: At what age } \\
\text { did you wear a for the opposite sex typical piece of clothing } \\
\text { for the first time? }\end{array}$ & & & 13.46 & \pm 10.90 & 159.5 & .938 (n.s.) \\
\hline 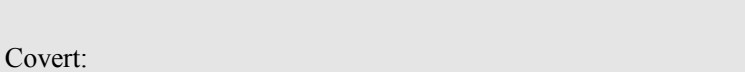 & & & Pub. & Pub. & & \\
\hline $\begin{array}{l}\text { Appear in public: } \\
\text { 3. How often did you use specific aids (e.g. wheelchair, } \\
\text { crutches) in the past } 12 \text { months (in review: } 12 \text { months before } \\
\text { surgical measures)? }\end{array}$ & 53.50 & \pm 162.50 & 25.50 & \pm 17.67 & 17.5 & $\leq .001$ \\
\hline $\begin{array}{l}\text { Number of hours per month: } \\
\mathrm{N}=19 \text { (BIID) } \\
\text { 4. How often did you wear the clothes of the desired sex in the } \\
\text { past } 12 \text { months (in review: } 12 \text { months before surgical } \\
\text { measures)? }\end{array}$ & & & 668.92 & \pm 210.64 & & \\
\hline $\begin{array}{l}\text { Number of hours per month: } \\
\mathrm{N}=12 \text { Gender Dysphoria }\end{array}$ & & & & & & \\
\hline
\end{tabular}

The results of the following hypothesis prove that both, BIID sufferers and transsexuals, show similarities concerning the development of the desire in childhood and early adolescence. The subjects in both samples stated that doubts about their identity had started at the age of 10 to 13 years (see above). These results support the findings concerning the possible age of onset in childhood and adolescence in Gender Dysphoria [1,12,13] and BIID [2,4,16] and correspond with a developing identity in this time. In case of Gender Dysphoria aspects of puberty may be involved in determining their wish and doubts about their identity at the age of 12.50 and 13 years.

The investigation of pretending and cross-dressing behavior showed that a long time before surgical changes, the desired appearance in both groups is imitated for approximation and testing of the desired physical condition (see Table 4).

A significant difference was found for pretending or cross-dressing concerning the number of hours that the subjects spent on that in the past 12 months, or in retrospect, 12 months before the receipt of surgical measures (see Table 4). This result, however, is to be regarded critically, because transsexuals must perform a real-life test about 1.5 years before obtaining surgery in Germany. The real-life test takes place in all parts of daily life and requires that the client is constantly living in the desired gender role [1]. This leads to an increased number of hours and explains the significant differences in this question. 
For the next hypothesis, the assumption was confirmed that both, BIID sufferers as well as transsexuals, believe they can live in accordance with the desired identity only by surgery. Psychotherapy, however, was in both samples considered to be of little help with regard to the acceptance of one's body. Only in the study of Thiel et al. [18], it could be concluded that psychotherapy (in BIID) is able to help dealing with the desire and its intensity.

For transsexual clients psychotherapeutic support is part of the preparation for a life in the opposite sex and aims less in the direction to resolve the request. It rather allows the client to address problems of social life that are related to the real-life test $[1,19]$.

Within this therapeutic attendance the client can ultimately make the decision to adopt a course which includes hormonal therapy but not necessarily surgery [19].

For a further hypothesis significant group differences were detected concerning the assumption that erotic components reinforce the desire for a surgical body change.

Referring to the averages erotic components are expressed as reinforcing the desire. In previous studies it was found that BIID-subjects consider the relevance of erotic aspects for their desire to be secondary and that primary identity aspects are in the foreground $[2,4]$. The data collected in this study already speak for these opinions. For the transsexual participants the corresponding item was answered rather in the negative direction. Furthermore, the influence of erotic aspects to the desired body change concerns only a subset of transsexuals, primarily in the older ones. Erotic components are often linked to a history of a transvestite fetishism $[1,19]$. Lawrence [10] criticized that erotic components of both groups are denied under certain circumstances and that the aspect of socially desirable response behavior may also be a decisive factor.

For the last hypothesis presented in our study it could be confirmed that both, BIID sufferers and transsexuals, show similarities with regard to high psychological strain and limitations in their quality of life without surgery. For example, in case of Gender Dysphoria, the feeling of distress can cause illegitimate hormone replacement therapy [1].

\section{Limitation of the findings}

The generalization of the results is limited due to the small sample size and the different gender ratio. In the sample of BIID sufferers only one female subject was included in the investigation and there were 12 female and seven male participants in the sample of the transsexuals. This is also reflected in the significance of the Chi-Square test. In case of an already completed gender reassignment surgery or obtained amputation/impairment, the subjects were asked, to assess all items retrospectively from a point of time previous to this intervention. This poses a risk of contorted answers. Additional, both groups differed significantly in terms of sex and in the number of subjects who already achieved surgical or other changes and those who did not yet achieve these changes. This may also have an impact on our findings.

\section{Conclusion}

Despite these limitations, the results of this small pilot study are of high importance because this is the first study in which similarities and differences between BIID and Gender Dysphoria were investigated. In summary, the results argue for a firmly established sense of identity in BIID and Gender Dysphoria.

Consequently, in our mind, the assumption of M. First (2005) is supported that BIID may be a new kind of identity disorder. However, the results should be re-examined based on a larger sample.

\section{References}

[1] Beier, K. M., Bosinski, H. \& Loewit, K. (2005). Sexualmedizin (Vol. 2). München, Jena: Urban \& Fischer Verlag, Elsevier $\mathrm{GmbH}$.

[2] Blanke, O., Morgenthaler, F. D., Brugger, P. \& Overney, L. S. (2008). Preliminary evidence for a fronto-parietal dysfunction in able bodied participants with a desire for limb amputation. Journal of Neuropsychology, 124, 1-13.

[3] Dua, A. (2010). Apotemnophilia: ethical considerations of amputating a healthy limb. J Med Ethics, 36, 75-78.

[4] First, M. (2005). Desire for amputation of a limb: paraphilia, psychosis, or a new type of identity disorder. Psychological Medicine, 35, 919-928.

[5] First, M. \& Fisher, C. (2012). Body Integrity Identity Disorder: The Persistent Desire to Acquire a Physical Diability. Psychopathology, 45, 3-14.

[6] Haupt, H.-J. (2012). "Sie sind ihr Gehirn - Transsexualität im Spannungsfeld von Neurowissenschaft und Transphobie"Lecture presented on Trans*Identitäten, Wien. Access on 28.02.2014. Available in http://www.trans-evidence.com/Neuro_Transphobie.pdf

[7] Hilti, L. M. \& Brugger, P. (2010). Incarnation and animation: physical versus representational deficits of body integrity. Exp Brain Res, 204, 315-326.

[8] Kasten, E. (2009). Body Integrity Identity Disorder (BIID): Befragung von Betroffenen und Erklärungsansätze. Fortschr Neurol Psychiat, 77, 16-24.

[9] Kasten, E. (2012). Body Integrity Identity Disorder Körperidentität durch erwünschte Behinderung. Psychiatrie und Psychotherapie up2date, 6 (3), 165-176.

[10] Lawrence, A. A. (2006). Clinical and Theoretical Parallels between Desire for Limb Amputation and Gender Identity Disorder. Archives of Sexual Behavior, 35, No. 3, 263-278

[11] Manok, A. (2012). Body Integrity Identity Disorder. Die Zulässigkeit von Amputationen gesunder Gliedmaßen aus rechtlicher Sicht (Vol. 1). Leipzig: Leipziger Universitätsverlag.

[12] Möller, B., Schreier, H. \& Romer, G. (2009). Geschlechtsidentitätsstörungen im Kindes- und Jugendalter. Z Sexualforsch, 22, 227-254.

[13] Nieder, T. et al. (2011). Age of Onset and Sexual Orientation in Transsexual Males and Females. J Sex Med, 8, 783-791. 
[14] Nieder, T. O. \& Richter-Appelt, H. (2009). Parallels and Differences between Gender Identity Disorders (GID) and Body Integrity identity Disorder (BIID) and Implications for Research and Treatment of BIID. In Stirn A., Thiel A. \& Oddo S. (Ed.), Body Integrity Identity Disorder: Psychological, Neurobiological, Ethical and Legal Aspects (pp. 133-138). Lengerich: Pabst Science Publishers.

[15] Stirn, A., Thiel, A. \& Oddo, S. (2009). Body Integrity Identity Disorder: Psychological, Neurobiological, Ethical and Legal Aspects. Lengerich: Pabst Science Publishers.

[16] Stirn A., Thiel A. \& Oddo S. (2010). Body Integrity Identity Disorder (BIID). Störungsbild, Diagnostik, Therapieansätze (Vol. 1). Weinheim, Basel: Beltz Verlag.
[17] Söder, M. (1998). Düsseldorfer Fragebogen zur Transidentität. In: Die Strukturen der Herkunftsfamilien weiblicher Transsexueller und deren Vergleich mit einer Stichprobe von Frauen kongruenter Geschlechtsidentität. Unpublished diploma thesis, Psychologisches Institut der Mathematisch-Naturwissenschaftlichen Fakultät der Heinrich-Heine-Universität Düsseldorf

[18] Thiel, A., Ehni, F. J. F., Oddo, S. \& Stirn, A. (2011). Body Integrity Identity Disorder: Erste Erfolge in der Langzeitpsychotherapie. Psychiat Prax, 38, 256-258.

[19] Vetter, B. (2007). Sexualität: Störungen, Abweichungen, Transsexualität (Vol. 1). Stuttgart, New York: Schattauer Verlag. 